\title{
THE EFFECT OF CARRIER GASES ON CNTS GROWTH BY FLOATING CATALYSIS METHOD THROUGH PYROLYSIS OF FERROCENE
}

\author{
WANLIANG MII*1, DONGMEI JIA ${ }^{2}$ \\ ${ }^{1}$ Department of Thermal Science and Energy Engineering, University of Science and Technology Beijing, Beijing City 100083, \\ China 2. China National Chemical Information, Beijing City 100083, China
}

(Received: August 1, 2008 - Accepted: March 25, 2010)

\begin{abstract}
CNT arrays grew on macroporous substrate for different time in the ammonia and nitrogen carrier gases by floating catalyst method. Scanning electron microscope (SEM) and Transmission electron microscope (TEM) were used to characterize the morphology of the CNTs supported on porous substrate. Experimental results show that the vertically aligned CNT could grow on the macroporous substrate. Carrier gases have obviously effect on the diameter and growth rate of CNTs. Both growth time and diameter of CNTs are the key factors to keep the vertically aligned CNTs growth.
\end{abstract}

Keywords growth mechanism, vertically aligned CNT, porous substrate, floating catalyst method

\section{INTRODUCTION}

Vertically aligned CNTs arrays have many applications, such as in vacuum microelectronics [1], flat panel displays [2] and membrane separation [3]. Aligned CNTs on different substrate is of vary applications, especially on porous substrate.

Singh [4-6] used a mixture of argon and 10\% hydrogen as the carrier gas to produce aligned carbon nanotubes on a quartz substrate in large scale by the CVD injection method. Zhang [7] also prepared aligned CNTs with the help of cobalt powder quartz-glass tube using the same carrier gas as Singh, which experimental results showed that the reaction temperature significantly influenced the alignment and diameter of the CNTs. And more literatures reported the preparation of aligned CNTs in pure hydrogen and argon $[8,9]$.

In fact, the carrier gases have some effect on the aligned CNT growth, especially for the reactive gases, such as $\mathrm{NH}_{3}$. Jung [10] deposited $\mathrm{Ni}$ and $\mathrm{Co}$ particles on $\mathrm{SiO}_{2} / \mathrm{Si}$ substrate, and grew CNTs by thermal CVD method, which shows that the activated nitrogen atoms generated by $\mathrm{NH}_{3}$ decomposition is an important factor to enhance aligned CNT growth in $\mathrm{NH}_{3}$ environment.

For the method of pre-depositing catalyst powders on smooth and dense substrate, then growth aligned CNTs on it by pyrolysis of carbon-contain materials using $\mathrm{CVD}$, the $\mathrm{NH}_{3}$ helps to maintain catalyst metal surface active by reacting with amorphous carbon. But for the macroporous substrate, it is difficult to prepare aligned CNTs arrays on it because of the surface roughness. We have attempted several methods to produce vertically aligned CNTs [11]. Experimental results shows that vertically aligned CNT films could not be obtained by the methods of preloading catalyst, except for the chemical vapor deposition with the alumina substrates exposed in the quartz tube by flowing catalyst method. The carrier gases should also give some influence on CNTs growth.

No work on effect of carrier gases on the vertically aligned CNTs growth prepared by floating catalysis method on macroporous substrate has been reported. This communication reports the different growth status of CNT and mechanism of growing vertically aligned CNTs in $\mathrm{NH}_{3}$ and $\mathrm{N}_{2}$ environmental gas by pyrolysis of ferrocene respectively.

\section{EXPERIMENTAL}

The macroporous $\alpha-\mathrm{Al}_{2} \mathrm{O}_{3}$ disk preparation and CNTs growth on the substrate were showed as our former paper [11]. But the CNTs growth time and carrier gases environment are different. In this method, a macroporous $\alpha-\mathrm{Al}_{2} \mathrm{O}_{3}$ disk was horizontally placed in the second-zone of the two-zone quartz reactor. Ferrocene as catalyst precursor was placed in the first-zone and heated to its sublimed temperature. The sublimed ferrocene was carried to the substrate and deposited on it by carrier gas, such as ammonium or nitrogen gas at a flow rate of $100 \mathrm{cc} / \mathrm{min}$. Ferrocene decomposed and formed the nanoparticles at $800^{\circ} \mathrm{C}$, which are the key factors for CNTs growth. Acetylene as carbon resource was introduced into the quartz reactor at a flow rate of $10 \mathrm{cc} / \mathrm{min}$ after the ferrocene deposition for two minutes.

Scanning electron microscope (SEM) images were recorded on the asdeposited samples using a Philips XL 300ESEM instrument, to check the nature of alignment and morphological characteristics of aligned nanotube bundles. In order to protect the original morphology of the sample, it was placed into a glass utensil after reactions without touching its surface. Transmission electron microscope (TEM) images were obtained with a JEOL-JEM-100CXII electron microscope.

\section{RESULTS AND DISCUSSION}

Fig. 1 compares the SEM images of CNTs grown on the substrate in $\mathrm{NH}_{3}$ at $800{ }^{\circ} \mathrm{C}$ for $1 \mathrm{~min}(\mathrm{~A}), 5 \mathrm{~min}(\mathrm{~B}), 7 \mathrm{~min}(\mathrm{C})$ and $10 \mathrm{~min}(\mathrm{D})$ respectively, showing the CNTs difference in alignment and tube length. Fig. 1 shows that as the growth time increasing, the CNTs alignment became better. CNTs initially grew in the random direction on the support after catalyst cores forming (Fig.1A). The lager particles about $1.5 \mathrm{~mm}$ in diameter in Fig. 1(A) are the submicronsized $\alpha-\mathrm{Al}_{2} \mathrm{O}_{3}$ crystalline particles. And the little white particles about $100 \mathrm{~nm}$ in diameter are the nanocatalyst particles. Some CNTs grew vertically on the substrate; and some CNTs nearly grew parallel to the substrate as shown in Fig. 1(A). After growth for about 5 min, CNTs alignment became better as those CNTs were forced to align vertically by the steric hindrance from neighbor nanotubes around it. But amount of CNTs still grew randomly instead of vertically on the substrate. After growing for ten minutes, the CNTs alignment becomes much better (See Fig. 1(D)) than before. Fig. 1 (D) showed the vertical CNTs with about $10 \mathrm{~mm}$ in tube length giving that CNT growth rate of about $1 \mathrm{~mm} / \mathrm{min}$. CNTs growth rate is nearly same at different growth stage.

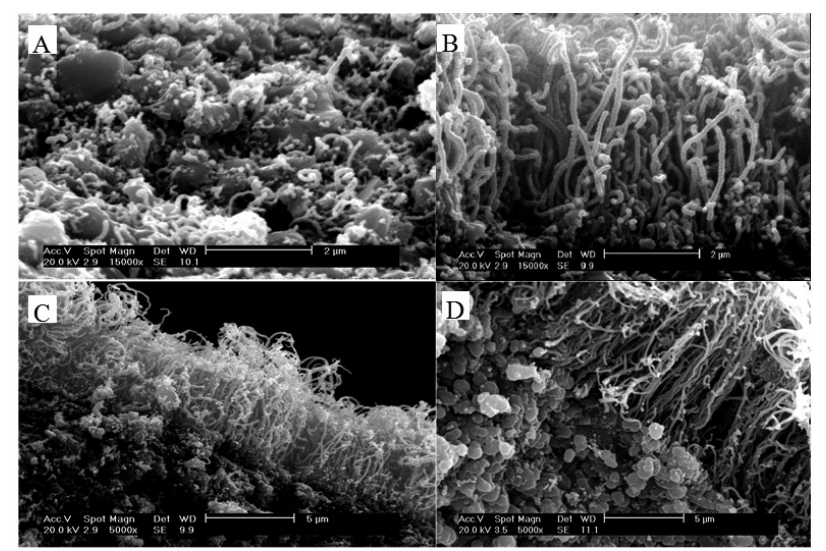

Fig. 1 SEM images of aligned CNTs grown on the substrate in $\mathrm{NH}_{3}$ at 800 ${ }^{\circ} \mathrm{C}$ for $1 \mathrm{~min}(\mathrm{~A}), 5 \mathrm{~min}(\mathrm{~B}), 7 \mathrm{~min}(\mathrm{C})$ and $10 \mathrm{~min}(\mathrm{D})$ respectively.

TEM micrograph of CNTs scraped from the substrate after CVD at $800^{\circ} \mathrm{C}$ shows that the CNT diameter is also important in ensuring aligned growth of CNT films except for CNTs growth time. The diameter of CNTs should reach a critical value. For example, Ren ${ }^{[7]}$ et al. suggested a critical CNTs diameter of 
about $50 \mathrm{~nm}$ for aligned growth of CNTs. Average diameter of CNTs prepared by our lab is about $100 \mathrm{~nm}$. The catalyst density on the support is different on the above two kinds of support (for example, one is the porous ceramic, the other is the quartz).
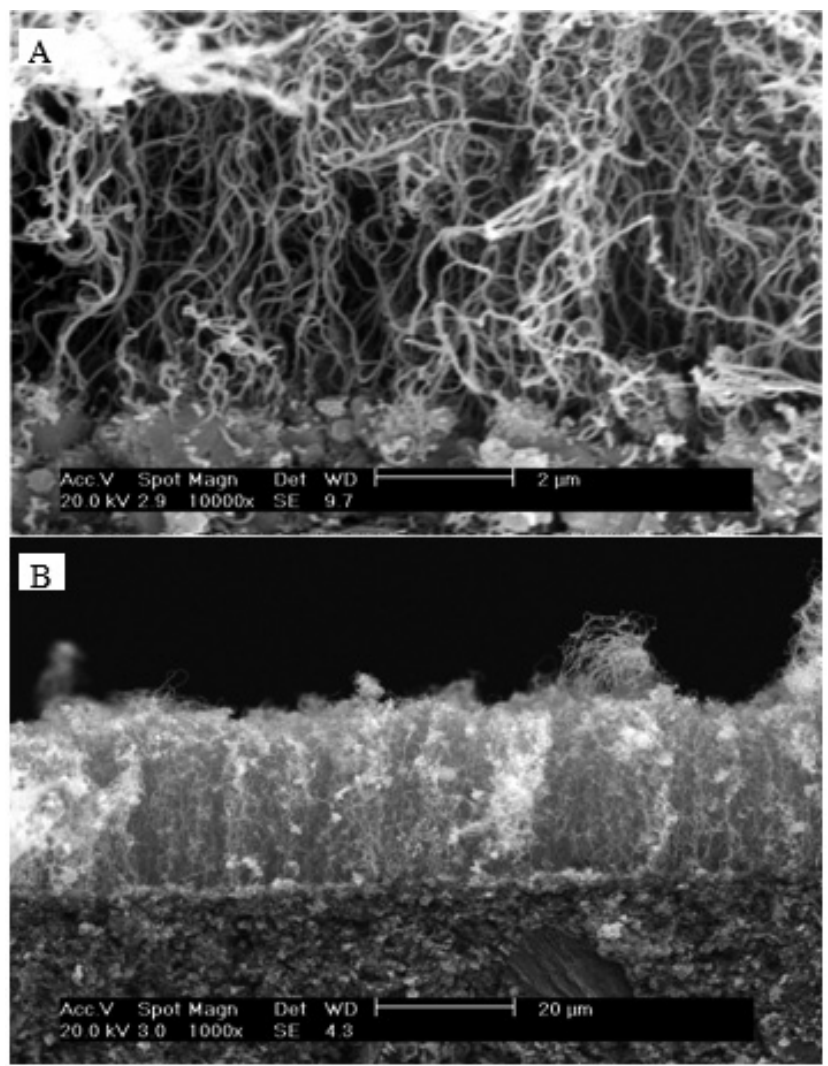

Fig. 2 SEM images of not well-aligned CNTs grown on the substrate in $\mathrm{N}_{2}$ at $800{ }^{\circ} \mathrm{C}$ for $5 \min (\mathrm{A})$ and $10 \mathrm{~min}(\mathrm{~B})$ respectively.

Fig. 2 gives the SEM images of not-well aligned CNTs grown on the substrate in $\mathrm{N}_{2}$ at $800{ }^{\circ} \mathrm{C}$ for $5 \mathrm{~min}$ (A) and $10 \mathrm{~min}$ (B). TEM results showed that the CNTs were below $90 \mathrm{~nm}$ in diameter. The CNTs diameter is smaller than that grown in $\mathrm{NH}_{3}$, So the alignment is not as good as that grown in $\mathrm{NH}_{3}$ even for the same growth time. CNTs have much tortuosity even if the steric hindrance from the adjacent nanotubes via the Van der Waals force among CNTs at the first five minutes growth. As growth time increasing, CNTs still have tortuosity, though smaller than before. They could not grow very well aligned. CNT growth rate is about $2 \mathrm{~mm} / \mathrm{min}$ in this condition, two times more than that in $\mathrm{NH}_{3}$ gas.

Comparison figure 1D with figure 2B, we could see that the CNTs growth with same time in $\mathrm{N}_{2}$ and $\mathrm{NH}_{3}$ carrier gases is different from the length and diameter. It is bigger and shorter in the average diameter and length for the CNTs growth in $\mathrm{NH}_{3}$ than that in $\mathrm{N}_{2}$ gas environment respectively. Here, we find an inverse relation between the diameter and growth rate of carbon nanotubes, which is suitably explained by the inhibiting CNTs growth effect of $\mathrm{NH}_{3}$ gas.

Fig. 3(A) is the TEM image of CNTs grown on the $\alpha-\mathrm{Al}_{2} \mathrm{O}_{3}$ substrate. The big and black section in the figure is the $\alpha-\mathrm{Al}_{2} \mathrm{O}_{3}$ substrate. Though the CNTs were dealt with in ultrasonic ethanol bath for a short time, CNTs with high density still kept vertically aligned on the substrate as a result of the Van de Waals force among the CNTs, while CNTs with low density showed distorted. This confirms that it was the Van der Waals force among CNTs that made the CNTs aligned. In fact, the CNT growth is constrained by its neighbor CNT as Fig. 3(B) shown, which lead to the aligned growth.

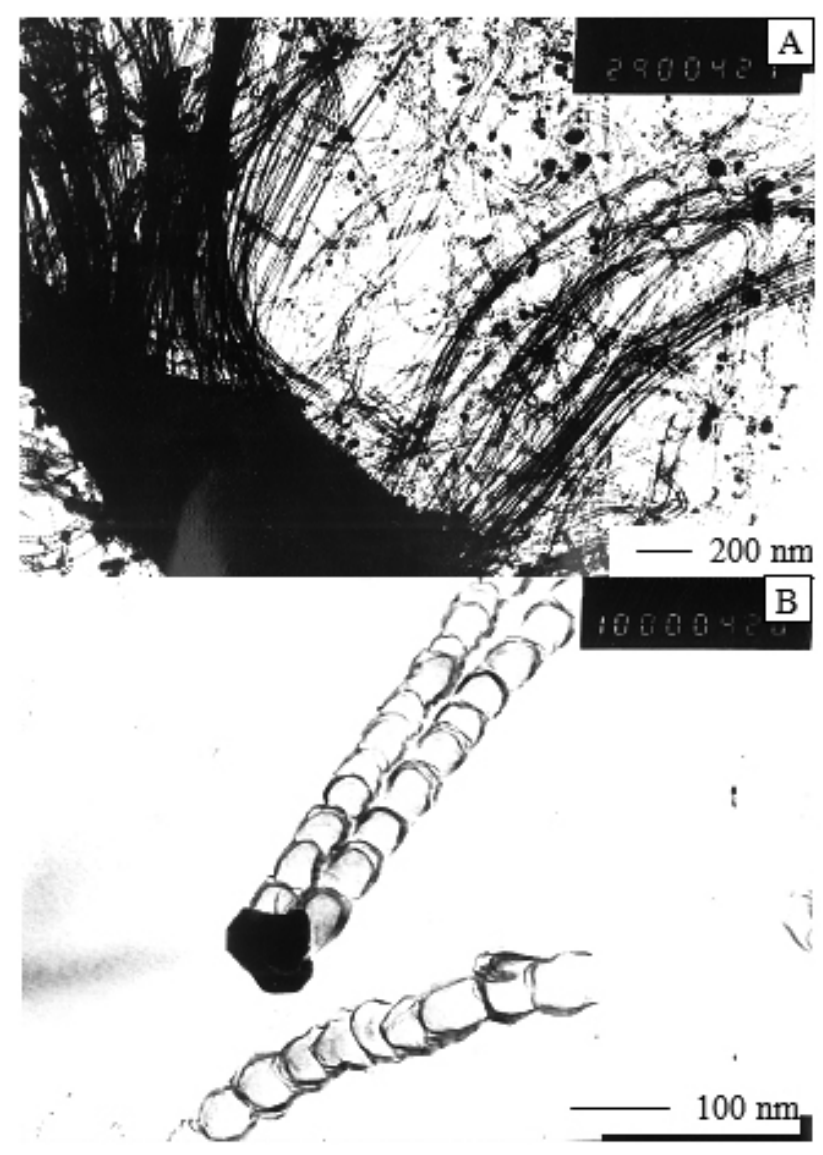

Fig. 3 TEM image of CNTs grown on the a- $\mathrm{Al}_{2} \mathrm{O}_{3}$ substrate.

Researchers have debated whether an individual catalyst particle produces an individual nanotube, which later bundles up with other nanotubes, or the individual catalyst particle produces a number of nanotubes bundled together from the root. There have been observations that support each of the two possibilities. For example, Gavillet and co-workers [12,13] have reported convincing TEM images that show bundles of SWNT growing from a common catalyst particle. At the same time, Li et al. [14] have reported equally convincing images of individual SWNT produced by individual metal particles, whose size in turn determines the nanotube diameter. In this experiment, the former condition occurs as seen clearly in Fig.3 (B). In fact it depends on the nature of the catalyst and the reaction conditions.

\section{CONCLUSIONS}

In summary, carrier gases have significant effect on growth status of CNTs arrays prepared by flowing catalysis method. CNTs could grow vertically aligned on the macroporous substrate when CNT density is enough as much as possible (100 nm in this paper). Both growth time and diameter of CNTs are important for insuring the CNTs alignment. The growth rate is enhanced with an inverse dependence of the CNTs diameter by comparison with two kinds of carrier gases. Diameter of CNTs grown in $\mathrm{NH}_{3}$ gas is bigger than that in $\mathrm{N}_{2}$ gas.

\section{ACKNOWLEDGEMENTS}

This work was supported by National Natural Science Foundation of China (No. 20776016) and Cheung Kong Scholar Program (No. 50228203) 


\section{REFERENCES}

S. J. Tans, A. R. M. Verschueren, C. Deklar, Nature. 393, 49, (1998)

P. M. Ajayan, T. W. Ebbesen, Rep. Prog. Phys. 60, 1025, (1997)

B. J. Hinds, N. Chopra, R. Rantell, R. Andrew, V. Gavalas, L. G. Bachas, Science. 303, 62, (2004)

C. Singh, Milo S.P. Shaffer, Krzysztof K.K. Koziol, I. A. Kinloch, A. H. Windle, Chemical Physics Letters. 372, 860, (2003)

C. Singh, Milo S.P. Shaffer, A. H. Windle, Carbon. 41, 359 (2003)

C. Singh, Milo Shaffer, I. Kinloch, A. Windle, Physica B. 323, 339 (2002)

H. Zhang, E. Liang, P. Ding, M. Chao, Physica B, 337, 10 (2003)

H. Hou, A. K. Schaper, Z. Jun, F. Weller, A. Greiner, Chem. Mater. 15, $580,(2003)$
Y. T. Lee, N. S. Kim, J. Park, J. B. Han, Y. S. Choi, H. Ryu, H. J. Lee, Chemical Physics Letters. 372, 853, (2003)

M. Jung, K. Y. Eun, Y. J. Baik, K. R. Lee, J. K. Shin, S. T. Kim, Thin Solid Films. 398 - 399, 150, (2001)

W. L. Mi, Y. S. Lin, Y. D. Li, B. Q. Zhang, Microporous and Mesoporous Materials. 81, 185, (2005)

J. Gavillet, J. Thibault, O. Stéphan, H. Amara, A. Loiseau, Ch. Bichara, J. P. Gaspard, F. Ducastelle, J. Nanosci. Nanotech. 4, 346, (2004)

J. Gavillet, A. Loiseau, C. Journet, F. Willaime, F. Ducastelle, J. C. Charlier, Phys. Rev. Lett. 87, 2755041, (2001)

Y. M. Li, W. Kim, Y. G. Zhang, M. Rolandi, D. W. Wang, H. J. Dai, J. Phys. Chem. B. 105, 11424 (2001). 